\title{
Development of Primary Care Research in North America, Europe, and Australia From 1974 to 2017
}

Florence Hajjar, MD ${ }^{1}$

Olivier Saint-Lary, $M D, P b D^{2,3}$

Jean-Sébastien Cadwallader, MD, $P h D^{1,4}$

Pierre Chauvin, $M D, P b D^{4}$

Alexandre Boutet, $M D^{5}$

Magali Steinecker, $M D^{1}$

Sarab Robert, $M D^{1,4}$

Gladys Ibanez, $M D, P b D^{1,4}$

'School of Medicine, Department of General Practice, Sorbonne University, Paris, France

${ }^{2}$ Department of Family Medicine, Faculty of Health Sciences Simone Veil, University Versailles Saint-Quentin en Yvelines (UVSQ), Montigny-le-Bretonneux, France

${ }^{3}$ CESP, University Paris-Sud, University Paris-Saclay, Villejuif, France

${ }^{4}$ Sorbonne Universités, Institut Pierre Louis d'Épidémiologie et de Santé Publique Paris, France

${ }^{5}$ Inter-University Health Library, MedicineOdontology Center, Paris, France

Conflicts of interest: authors report none.

\section{CORRESPONDING AUTHOR}

Gladys Ibanez

Sorbonne Universités,

UPMC Univ Paris 06

INSERM, Institut Pierre Louis

d'Épidémiologie et de Santé Publique

(IPLESP UMRS 1136)

F75012, Paris, France

gladys.ibanez@upmc.fr

\begin{abstract}
Research is a necessity for high-quality medicine. We used the MEDLINE database to conduct a bibliometric analysis of research output with respect to primary care by 21 countries. For the period 1974 to 2017, the United States and the United Kingdom stood out in terms of publication volume, and the UK, Canada, and Australia had the greatest percentage of publications in primary care. As of 2017, publications in primary care represented a small proportion of total publications. The countries with the greatest publication productivity possess factors that should be considered with respect to strengthening research in primary care.

Ann Fam Med 2019;17:49-51. https://doi.org/10.1370/afm.2328.
\end{abstract}

\section{INTRODUCTION}

I n a 2008 report the World Health Organization underscored the need to develop the production of knowledge and research work in primary care (PC). ${ }^{1}$ Several studies have been conducted to assess the production of research work in PC, for example in Germany, Australia, and Egypt. ${ }^{2-4}$ Two studies have been performed internationally, the first conerning the development of research in PC from 1975 to 2003 in 4 Nordic countries, 7 European countries, and 7 other countries ${ }^{5}$ and the second concerning the development of research in PC from 2001 to 2007 in 6 countries (Australia, Canada, Germany, the Netherlands, the UK and the US). ${ }^{6}$

Our intention was to update and expand information regarding the field of research in PC. The objective was to conduct a situational review and an analysis of the publication productivity in PC in North America, Europe, and Australia, so as to have socioeconomically comparable countries.

\section{METHODS}

We performed a quantitative bibliometric study of the MEDLINE database for January 1, 1974 to December 31, 2017. The MEDLINE database is the US National Library of Medicine journal citation database. The Medical Subject Headings (MeSH) is the reference thesaurus in the biomedical domain. The term Primary Health Care was first entered as a MeSH term in 1974. We selected European countries for which the Human Development Index was $>0.85$, then classified them according to the United Nations geoscheme for Europe. Twenty-one countries were included in our analysis: Austria, Australia, Belgium, Canada, Cyprus, the Czech Republic, Denmark, Estonia, Finland, France, Germany, Greece, Ireland, Italy, Luxembourg, the Netherlands, Slovenia, Spain, Sweden, the UK, and the United States.

After reviewing the websites for each national PC and GP college for current/past terms related to PC, the bibliographic search strategy (conducted by F.H. and G.I.) included the following MeSH terms: family prac-

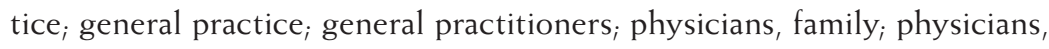
primary care, primary health care (Supplemental Figure 1, http://www. AnnFamMed.org/content/17/1/49/suppl/DC1/). Only research articles were included in this analysis. 
Figure 1. Number of publications in primary care (1974-2017).

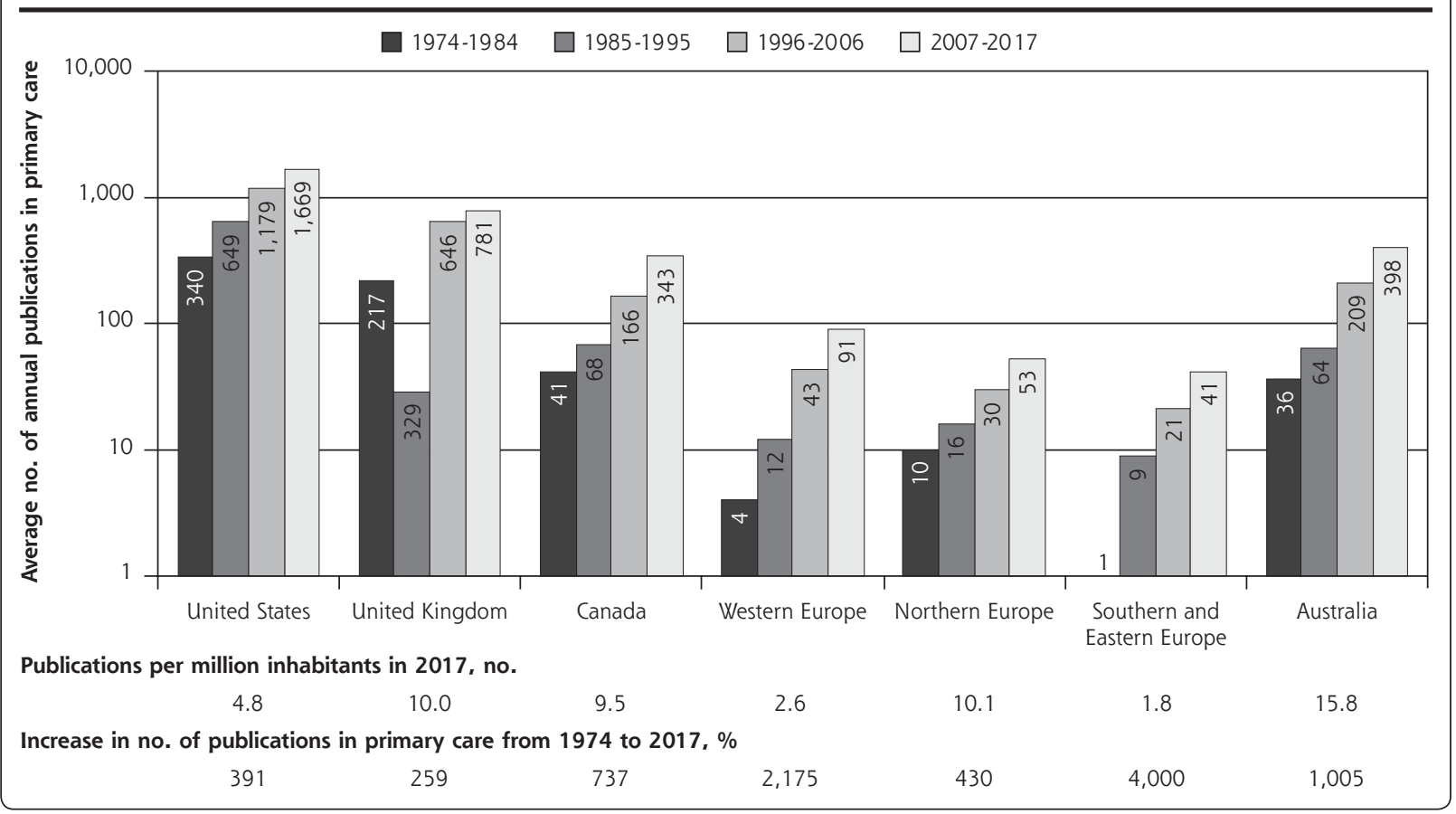

The publication numbers for each country were charted on a semilogarithmic scale. We then divided the publication numbers by the number of inhabitants for each country or region of Europe (from latest available official data [2017]), to obtain an average number of publications per million inhabitants. To take into account the general increase in publications in MEDLINE over time, the number of publications in PC was compared with the total number of publications per country/region in 1974 and 2017. The increase in the number of publications in PC was calculated, as was the increase in the total number of publications. The increase in the ratio of the number of publications in $\mathrm{PC}$ to the total number of publications in MEDLINE was calculated per country/region.

\section{RESULTS}

Figure 1 shows the development of publications in PC from 1974 to 2017 (detailed in Supplemental Table 1). The US and the UK stood out in terms of publication volume, with Canada and Australia having relatively large publication volumes. In 2017, Australia as well as the Northern European countries and the UK had the greatest numbers of publications per million inhabitants. Increases over time were greatest for the Southern, Eastern, and Western European countries.

The percentage of publications in PC relative to all publications in MEDLINE for each country/region is shown in Figure 2. From 1974 to 2017, the UK and
Australia showed the greatest percentage of publications in PC. Increases in percentage of publications in PC were greatest for the Southern, Eastern, and Western European countries.

Compared with the total number of publications in MEDLINE as of 2017, publications in PC represented a small proportion of publications.

\section{DISCUSSION}

Our objective was to assess 1 aspect of academic impact (ie, trends in research output). We found a gap in the development of research in PC across North America, Europe, and Australia. The US consistently showed the greatest volume of publications in PC. Several regions of Europe showed marked increases in publications. The UK, Australia, and Canada showed the greatest percentage of publications in $\mathrm{PC}$ compared to all publications in MEDLINE.

According to studies, there is a relative deficit of PC research. One study showed that between 1960 and 2003, PubMed citations in general practice amounted to $1 / 20$ th the number of citations in cardiology. ${ }^{7}$ This may be due to PC nosology, classification, lack of theory, lack of data models, lack of research culture, etc. Systematic referencing using PC codes $(\mathrm{MeSH}$, Emtree, etc) might lead to a better understanding of health systems across countries. The countries with the greatest publication productivity in the study possess factors that have strengthened research in PC and that should 
Figure 2. Number of publications in primary care relative to all publications in MEDLINE in 1974 and 2017.

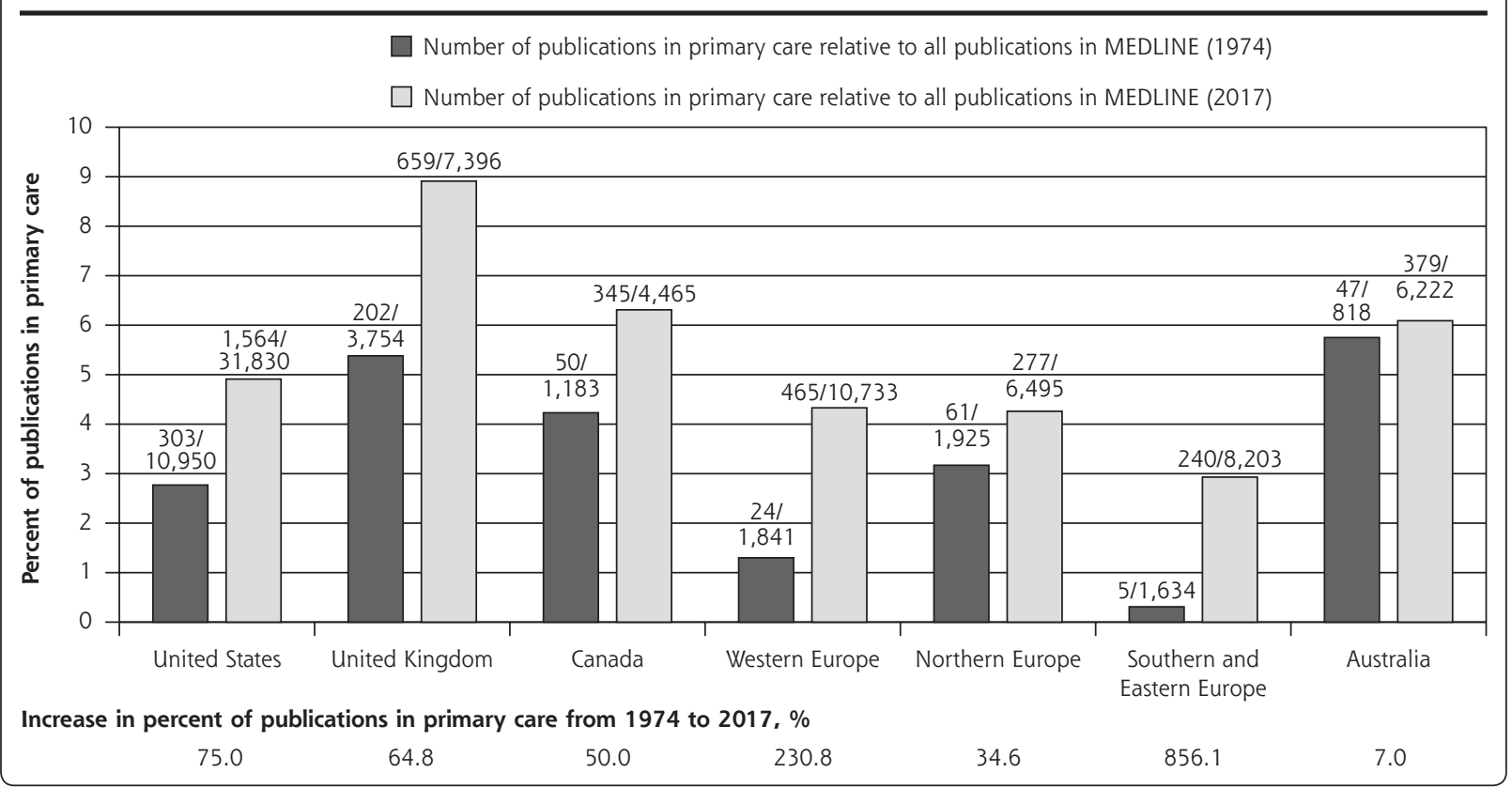

be considered. These include the importance of PC in the health care system and universities ; training and funding of PC researchers; strong professional and academic colleges; structuring of a national data collection network; structuring of PC research teams; favorable conditions for publishing in English; and international research networks and cooperation. ${ }^{8-10}$

The types of PC codes vary among countries, and comparison is limited by the existence of different types of health care organizations. Our results may reflect a degree of error if the publications are coded with disease names or categories of care populations. This type of error might not differ significantly among countries, however. The bibliographic search was specific to the history of MEDLINE. Early on, there were very few indexed PC/family medicine journals, and there was a bias against non-American journals. The slow inclusion of PC journals potentially provides an artificial increase in the numbers measured. Similar patterns, however, have been found in other databases (Supplemental Figure 2).

We believe that our results reflect the development of PC research, in particular the visibility of PC research, according to country/region. Comparisons of factors associated with better research development may help to define priorities.

To read or post commentaries in response to this article, see it online at http://www.AnnFamMed.org/content/17/1/49.

Key words: research report; primary care, family practice; general practice; general practitioners; physicians, primary care; primary health care; physicians, family
Submitted May 25, 2018; submitted, revised, August 31, 2018; accepted September 27, 2018.

Supplemental Materials: Available at http://www.AnnFamMed. org/content/17/1/49/suppl/DC1/.

\section{References}

1. World Health Organization. Primary Health Care - Now More Than Ever. Geneva, Switzerland: World Health Organization; 2008.

2. Schneider A, Großmann N, Linde K; DFG Network Clinical Trials in General Practice. The development of general practice as an academic discipline in Germany - an analysis of research output between 2000 and 2010. BMC Fam Pract. 2012;13:58.

3. Mendis $K$, Kidd MR, Schattner $P$, Canalese J. A bibliometric analysis of Australian general practice publications from 1980 to 2007 using PubMed. Inform Prim Care. 2010;18(4):223-233.

4. Abdulmajeed AA, Ismail MA, Nour-Eldein H. Research publications in medical journals (1992-2013) by family medicine authors - Suez Canal University-Egypt. J Family Med Prim Care. 2014;3(4):368-373.

5. Ovhed I, van Royen $P$, Håkansson A. What is the future of primary care research? Probably fairly bright, if we may believe the historical development. Scand J Prim Health Care. 2005;23(4):248-253.

6. Glanville J, Kendrick T, McNally R, Campbell J, Hobbs FDR. Research output on primary care in Australia, Canada, Germany, the Netherlands, the United Kingdom, and the United States: bibliometric analysis. BMJ. 2011;342:d1028.

7. Mendis K, Solangaarachchi I. PubMed perspective of family medicine research: where does it stand? Fam Pract. 2005;22(5):570-575.

8. Lionis C, Carelli F, Soler JK. Developing academic careers in family medicine within the Mediterranean setting. Fam Pract. 2004;21(5): 477-478.

9. Chaudhry Z, Mannan F, Gibson-White A, et al. Outputs and growth of primary care databases in the United Kingdom: bibliometric analysis. J Innov Health Inform. 2017;24(3):942.

10. Bowman MA, Lucan SC, Rosenthal TC, Mainous AG III, James PA. Family medicine research in the United States from the late 1960s into the future. Fam Med. 2017;49(4):289-295. 